\title{
COMMUNICATION AND CREATIVITY FOR PRESCHOOLERS
}

\author{
Dana DUGHI, Ph.D., \\ Liceul Special Sfânta Maria Arad \\ danadughi@yahoo.com \\ Simona IOJA, Professor Grădinița PP Pâncota \\ mona.ioja@yahoo.com
}

\begin{abstract}
The study we made has the purpose to reveal the way some of the techniques, methods and stimulation principles of creative features can be used on children. The study group contains children from the "big group". They have been involved in creative exercises like "Storytelling cubes", "Comic books", "Thinking hats" and other exercises based on synectic and brainstorming principles. The recorded results, after the game like or creative exercise evaluations, have revealed qualitatively changes of creative features like fluidity and flexibility.
\end{abstract}

Keywords: communication; creativity; divergent thinking; creative techniques;

\section{Theoretical premises and aplication principles}

The problem of creativity has become a concern in all sorts of areas. The being of creativity is vital in life, work, social relations, education. The main factor of creativity is not represented by intelligence or general knowledge, but by imagination and the non-intelectual personality features: epistemological interest, divergent thinking, curiosity, passion, will, decision, determination, motivation, trust, etc. In the development of creative characteristics obstractions may occur. They can be either of social and educational nature (stiffedtraditional education system, inhibited educational enviorment, based on memorizing and imitation, the society, the imperious political system), but also interpersonal (distorted self image, poor self knoledge, excesive shyness, distrust in own power of achievement). (Dughi, Roman, 2008)

The development of divergent thinking requires exercises which helps to incite the needed capacitys of creative thinking (Roco, M., 2001; Kelemen, G., 2007, Dughi, Ropotă, 2018):

- Verbal fluency - tell, within a given time, as many words possible, represeting objects, beings, animals, foodstuffs, etc. or words describing a certain sound.

- Ideally fluency - listen to the story, poem and give them as many titles as possible, find multiple usage of a sole object (paper, carpet, orange), answer to questions like: what would happened if...?

- Spacial skills - draw a flower using rectangles and circles.

By adopting the incorporated curriculum in the kindergarten, a great consideration is being given to children's creative and critical thinking development. For reaching the proposed purposes in education there are a few theories and methods to stimulate them. Most of them have general basic stimulation principles of creativity which derive from synectics and brainstorming.

The „Thinker's keys” method was introduced by Tony Ryan (1991). He names and describes several creative and criticak thinking strategies, like:

a) "The reverse" - place words such as cannot, never and not in sentences which you usually don't use: name 8 things that you could not touch; list 5 sounds that you have never heard; name 3 things that you could not photograph. 
b) „The What IF?" - you can ask virtually any What If question. They can be either serious or merry. What if there will be no more paper? What if there will be no water?Etc.

c) "The Disadvantages" - Choose an object, eg an umbrella, or a practice, eg playground duty, and list a number of its disadvantages. Then list some ways of correcting, or eliminating these disadvantages.

d) "The Combination” - children get to name a list of attributes of 2 dissimilar objects eg."magazineandswimming goggles" then combine the attributes into a single object.

e) "The BAR" -reinventing or redesigning everyday objects.

f) "The Alphabet” - Choose an object/word and compile a list of words from A to Z which have some relevance to the object/word.

g) „The Variations"-Start each question with "How many ways can you (make new friends, wash a giraffe, catch a gazele, etc.)

h) „The Picture”-The teacher draws a simple diagram which has no relevance to the area of study and the students then try to work out ways in which it could be linked with that area.

i) "The Prediction" -Ask for a series of predictions in regard to a particular situation, product or set of circumstances.Eg. Who will i be in 30 years? How will amusement parks look like in 100 years from now?Etc.

j) "The Different Uses”- we appeal to the notion of recycling, by naming several possible ways an object can be used (an old chair, a broken tv, an old shoe).

k) „The Ridiculous” - make a ridiculous, impossible statement, then students will have to give arguments to make the impossible possible, eg. Every child must pay taxes for each present from the Easter bunny.

In order to regain trust in own creative capacity, professor Annabella Cant (2010) suggests several ways, advices for exciting and waking creativity:

A. $\quad$ Free discussions of stundents - listen carefully to them, and take notes. Conversations with children stimulates our imagination and creativity; they hold a natural ability to make connections and create associations between elements that for us seem to be totaly different.

B. Write down right away ideas, pictures, behaviours, events, facts, processes, happenings etc. that you like and see on tv, in a paper, daily situations. The attempt to apply and adapt these new knowledge in daily educational cases.

C. Imagine your curricular activities before, without projecting it. Try to prepare interesting, unusual, exciting, extreme even, elements for each theme. These will stimulate both the stundent's and teacher's thought.

D. Insert ,Magic” in each educational moment.Magic offers us the posibility to escape our daily routine, but on the other hand, by stimulating our creative imagination, it manages to enrich our inner life.

E. Give students the possibility to offer for themselves ideas, aspects or initial elements to a theme. These kind of exercises give students the possibility to freely express themselves, unconstrained by the coerciveness of truth and reality's objectivity.

F. $\quad$ Trust your own intuition, proffessionaly, in your own educational instinct, because these will help you outline and develop brand new and personal ideas

G. Talk to people whom you believe are creative, and get inspired from their activity and experience. This is an efficient method to get methodological and professional enriched.

H. Do crosswords puzzles. A recreative activity, which helps practicing logical and creative thinking.

I. Write down as much as you can from what you live, see and read! The abundand colection of information, opinions and reflections will be the foundation generating new personal ideas. 
J. Don't get frightened by creativity. Try to conceive your new task from perspectives of enthusiasm, freedom and spontaneity proper to childhood, cutting out disruptive influences in the ongoing creative thinking.

2. Study goals

The study's main goal was to highlight the main factors that can stimulate the creative potential in preschoolers.

The specific goals were:

- Activating the required educational methodologies for growing creativity in preschoolers.

- Stimulating creative thinking by noticing and answering to certain learning situations.

3. General assumption

If the educational activities are setting goals and using techniques focused on creativity, then the development of creative features in preschoolers can be noticed.

\section{Research tools}

As research methods we've used the observation method and the productreview method.

The observation method - systematic, selective and continous observation. In the language teaching and practical skills activities, we have noticed children's creative acts in creative games regarding everyday themes.

The product review method - of all the products through which preschoolars creative potential reaches out $\mathrm{i}$ will analize storytelling and practical deeds. These two categories of products offers informations about the intelectual factors of creativity. From these factors we have chosen fluidity, flexibility and orgininality.

\section{$5 . \quad$ The group study describtion}

The group study has 21 preschool children from the „big group”. For the group study dates to be obvious and comparable we've developed activities in experiential DLC areas ( language and communication-storytelling area) and DOS ( human and society - practical skills area).

\section{Working variables \\ Independent variables:}

For the development of preschoolers creativity, games have been applied as tasks of creativity, destined to enhance the child's socio-emotional side; the „Storytelling cubes” creativity development method has been applied - children creating stories, with the help of cubes having certain object drawn on each side of the cube; the Brainstorming method - for group stimulation creativity, games that grow flexibility, creativiy and originality, different objects were handcrafted, collages during the practical skills activities.

\section{Dependent variables:}

After using dependent variables, creativity develops to preschooler children (originality, fluidity and flexibility).

\section{Research Design}

\section{Initial evaluation}

The study has been made during the second semester of the following school year 20172018.

The ascertaining experiment, as a preliminary step of the study, had the purpouse to identify the creative potential at children from the „,big group”. We have started with the premises that the preschooler's creative potential has general attributes as a base, which mainly belong to the intelectual, thinking and imaginative factor and that this is a variable ordinary distributed amongst children. We have taken as a basis of discussions the general creative potential, as it reflects itself in activities specific to the preschool child (language, practical skills). It contained tasks for the assesment of the preschoolers creativity level from the „big group” applied during clasical learning situations. In this way we have investigated fluidity, verbal 
and plastic flexibility at the students group. The methods used were the product review method (the story created by children, crafting an object with practical skills) and the „Comic book" task.

The main indices (dimensions) of potential creativity followed in this experimental step were: fluidity, flexibility, originality.

$>$ Fluidity reveals the ease and swiftness of association between new ideas, images, verbal flow, ideational ease and wealth; as sign of graphical fluidity we have taken into consideration the number of makeup elements.

$>$ Flexibility consist of an efficient reorganized way of thought according to new situations, in the possibility of handling certain transfers, in being able to give up old points of view and adopting new ones; as a sign of graphic flexibility we have taken into consideration the number of types of makeup elements.

$>$ Originality is being able to develop ideas, solutions, striking products, out of the ordinary; we have apreciated according to unusual makeup elements or thoughts in the students group.

The tasks of whose products were analized were: the story children have created, crafting an object and themed drawings.

Reviewing the products has been made by using the following scoring procedure:

- for figurative-plastic products (crafting an "object" and a drawing with a given theme, "Comic book" task)

- for each subject - we have analized and overall evaluated the drawings (within the group), under the aspect of the three dimensions (fluidity, flexibility, originality) using a Likert type scale with three steps. According to the Likert type scale, the lower scores show a lower level of the measured dimension, and high scores show a high level of that dimension:

-1 point-low level;

- 2 points-medium level;

- 3 points-high level.

The answers were thus rated:

1. for theverbal and plastic-figurative originalitydimension(valued by the unusual makeup elements in drawings, by the number of unusual, novel, rare drawings by group level, by the ways of work:

- 1 point -stereotypes elements;

- 2 points-fresh elements apear;

- 3 points-original, novel drawings.

2. for the verbal and figurative fluidity dimension (valued by the number of compositionalelements:

- 1 point-between one and three different elements;

- 2 points- between four and seven different elements;

- 3 points-over seven different elements.

3. for the verbal and figurative flexibility dimension (valued bythe number of categories in which the compositional elements belong toand by the number of types of objects represented with drawings, but also by the complexity of the story):

- 1 point - the elements belong in only one category;

- 2 points - the elements belong to two-three categories;

- 3 points-the elements belong in more than three categories.

\section{The subjects results in the ascertaining step}

At a first analisis of the results we have obtained, for the creativity's diagnosis task, the following frequency tabels -which synthesizes the rating occurance of each scoring version for the three dimensions of creativity (Tabel 1 ).

Tabel 1.Answering rating for the creativity's diagnosis tasks - „big group”. 
$(\mathrm{N}=21)$ (preliminary step)

\begin{tabular}{|c|l|c|c|c|}
\hline $\begin{array}{c}\text { Nr. } \\
\text { crt. }\end{array}$ & Dimensions & Low level & Medium level & High level \\
\hline 1. & Verbal and figurative fluidity & $5(30 \%)$ & $14(65 \%)$ & $2(5 \%)$ \\
\hline 2. & $\begin{array}{l}\text { Verbal and figurative } \\
\text { flexibility }\end{array}$ & $6(30 \%)$ & $12(55 \%)$ & $3(15 \%)$ \\
\hline 3. & $\begin{array}{l}\text { Verbal and figurative } \\
\text { originality }\end{array}$ & $3(15 \%)$ & $14(60 \%)$ & $4(25 \%)$ \\
\hline
\end{tabular}

By analizing the table we can see that, before the start of the formative experiment, creativity's dimensions at preschool children have recorded a medium level, as such:

- for the verbal and figurative fluidity almost two thirds of children (65\%) have been evaluated by having a medium level. Only two children (5\%) have recorded a high level at this dimension.

- for the verbal and figurative flexibility dimensions half of the children (55\%) have been evaluated by having a medium level verbal and figurative flexibility.Just three children $(15 \%)$ have recorded a high level at this dimension.

- for the verbal and figurative originality dimensions above half of the children (60\%) have been evaluated by having a medium level verbal and figurative originality. But, only four children $(25 \%)$ have recorded a high level at this dimension.

The creative element is missing in most of their works but also around the story, immitation being dominant, especially at children with low levels. Although they had the required materials within reach (cardboard, coated paper, wadding, matches, various beads, crushed ornaments, scissors, glue) they weren't able to create the suggested theme, only by immitation, although they knew the required techniques (gluing, cutting, assembling). During the story, no visual materials were used.

\section{The in fact experimental step. The teacher's intervension}

Educational activities have been developed in an incorporated manner on themed projects, according the preschool learning level for children in the „big group”.

The ,Storytelling cubes"

Is a technique through which group creativity and revelation of new is being stimulated, it was introduced in the development of educational process to different learning situations, also with the purpouse to enhance creativity to preschoolers. Starting from the idea that it offers the posibility of free, spontaneous acting of imagination by the group members, it grows the productivity of individual creativity, as a result of members interactions and them acting for a group solution, we have used it in applying the method going thru several steps.

The preliminary step contained four stages:

$>$ the stage of inquiring the group members and selecting them towards establishing the creative group;

$>$ the stage of creative practice, which consists in organising and familiarizing with the working techniques;

$>$ the stage of preparing the working sessions, in which the group's room has been arranged, a day time has been chosen, the necessary materials were checked, children have been told the rules, stages, the time of each child's intervention, mentioning that everyone will tell only one thought, even if they have several in mind, speaking one at a time. It will be allowed only the intervention of the ones who take an idea and develop it;

$>$ the productive stage of the creativity group, in which jumping ideas manifest, children don't criticize, don't extend the lenght of expression, try to issue as many own situations, new, to develop the coleagues ideas, to analize, to imagine. Interventions were made only 
when rules weren't followed and to encourage, stimulate, coordinate and to conduct childrens creative activity.

The method was applied to the language and communication domain activity taking the following stages:

$>$ The themathic setting stage - sets a minimum number of ,story” situations which must be made on the time unit (each child must use a figure from a side of the storytelling cube, and then continue the narrative thread by the classmate from the right), for the individual theme to become collective wearing the name „Story...”. Ideas told by every child were classified, partial synthesis were made and questions like these were asked: „What could we... change, add, combine, reverse, multiply, in our story?" and thus the preschoolars brain, being helped, answers by action. Each child, at a time, has brought original ideas that change the look of the story.

$>$ The stage of gathering additional ideas was made the next day, assuming keeping the „narrative thread" created by children on several days within the group with the purpouse of growing the issued ideas. In the same day, the step of sorting and selecting ideas took place, meaning the evaluation in which children are allowed to express their critical thinking, forbidden in the previous steps. At first, a list of ideas made by the group members was presented, and recorded in order of appearance: flat, sun, car, stoplight, flower, trail, bench, bridge, etc.

\section{The „Comic book" method}

The drawing activities with a chosen theme took place by grouping children in five-six groups containing six children. Each child received a chart and the necessary working tools. The theme was previously chosen. The attention was focused on the time given to the activity. Each child starts his drawing with the element he desires. The charts turn to the right, children retaking the idea and cotinuing it, making „comic books”.

\section{Final testing and data analizing}

The final step of the experiment consisted in applying tracing tasks to the level of creativity after the development of the experimental activity.

In the post experimental stepwe have applyed the same tasks again in the ascertaining experiment - tasks that targeted the diagnosis of creativity indexes (flexibility, fluidity, originality) in various experiential fields (language and communication, man and society practical skills).

After applying the tasks and analizing the data, the following results were obtained:

Tabel 2The mentioning frequency of each version $(\mathrm{N}=21)$ (postexperimental step)

\begin{tabular}{|r|l|c|c|c|}
\hline $\begin{array}{c}\text { Nr } \\
\text {.crt. }\end{array}$ & Dimensions & $\begin{array}{c}\text { Low } \\
\text { level }\end{array}$ & $\begin{array}{c}\text { Medium } \\
\text { level }\end{array}$ & $\begin{array}{c}\text { High } \\
\text { level }\end{array}$ \\
\hline 1. & $\begin{array}{c}\text { Verbal and figurative } \\
\text { fluidity }\end{array}$ & - & $11(50 \%)$ & $\begin{array}{c}10(50 \\
\%)\end{array}$ \\
\hline 2. & $\begin{array}{l}\text { Verbal and figurative } \\
\text { flexibility }\end{array}$ & $4(20 \%)$ & $12(60 \%)$ & $\begin{array}{c}5 \\
(20 \%)\end{array}$ \\
\hline 3. & $\begin{array}{l}\text { Verbal and figurative } \\
\text { originality }\end{array}$ & - & $4(20 \%)$ & $\begin{array}{c}17 \\
(80 \%)\end{array}$ \\
\hline
\end{tabular}

From the analisis of table 2 it can be noticed that there are differences regarding the way how they were evaluated and directly regarding the creative abilities they have showed in language and by making an object at practical skills, as such:

- at the verbal and figurative fluidity dimension, 10 children (50\%) were evaluated as having a high level verbal and figurative fluidity. None of the children has been recorded at a low level at this dimension, compared with $4(20 \%)$ in the inital stage. 
- at the verbal and figurative flexibility dimension, 5 children $(20 \%)$ were evaluated as having a high level verbal and figurative flexibility. Instead only 4 children (20\%), compared with $8(40 \%)$ from the initial stage, have been recorded at a low level at this dimension.

- at the verbal and figurative originality most children (80\%) were evaluated as having a high level verbal and figurative originality. This dimension however has known a development compared to the initial stage, so that no child was recorded as having a low level at this dimension.

\section{Conclusions}

The development of creative potential cannot be made by itself, but it needs actions that are continous and organized by stimulation and activation. Activating and stimulating the creative potential enforces its specific and growing level, age and individual particularities of the child and decisive relations, in which creativity is involved. In the same time, not any kind of learning activity allows the develoment of the creative potential, but only the active learning based on questioning, discovery, exploration.

This is the aspect we tried to show in this study through which, by using certain techniques, exercises and favourable attitudes toward developing creative features, qualitative changes of them were recorded at children. Still, the limits of this study must be mentioned: the low number of subjects, the low capacity of isolating the experimental variables, the relative objectivity of the evaluations of the creative features, the subjectivism of the evaluation items, the non-standardization of the creative features evaluation tasks.

Beyond this limits remains the importance of highlighting some techniques, principles and working situations with children in the way of supporting some features like critical thinking, divergent thinking, flexibility in thinking, the courage to express own ideas, the motivation to discover, these strategies being accessible to any teacher, no matter the age of children they are working with.

\section{References}

Cant, Annabella, (2010) Educaţia preşcolară privită cu alţi ochi, Ed.Risoprint, Cluj-Napoca Cant ,Annabella, Leva,Viorica,Tătaru Lolica, (2010) Dragă,educatoarea mea:modele de proiecte tematice cu integrarea narativă a conţinuturilor curriculare, Ed.Diamant, Piteşti Dughi,T., Roman, A. (2008) Dimensiuni psihologice ale învăţării, Arad, Ed. Universităţii Aurel Vlaicu

Dughi, T., Ropotă,C., (2018),Particularities of the development of thinking and language in pre-schoolers, Journal Plus Education, Vol XIX, nr. 1, pp. 207-219

Roco, M. (2001) Creativitate şi inteligenţă emoţională. Iaşi: Ed. Polirom

Ryan, T. (1990) Thinkers Keys for Kids, South Coast Education Region, Queensland 